for

\title{
Facile Room-Temperature Synthesis of Cerium Carbonate and Cerium Oxide Nano- and Microparticles Using 1,1'- Carbonyldiimidazole and Imidazole in a Nonaqueous Solvent
}

\author{
Seung Woo Choi ${ }^{1}$, and Jaeyun $\mathrm{Kim}^{1,2,3,4^{*}}$ \\ ${ }^{1}$ Department of Health Sciences and Technology, Samsung Advanced Institute for Health \\ Sciences \& Technology (SAIHST), Sungkyunkwan University (SKKU), Seoul 06355, \\ Republic of Korea
}

${ }^{2}$ School of Chemical Engineering, Sungkyunkwan University (SKKU), Suwon 16419, Republic of Korea

${ }^{3}$ Biomedical Institute for Convergence at SKKU (BICS), Sungkyunkwan University (SKKU), Suwon 16419, Republic of Korea

${ }^{4}$ Institute of Quantum Biophysics (IQB), Sungkyunkwan University (SKKU), Suwon 16419, Republic of Korea

*Correspondence should be addressed to J. Kim (kimjaeyun@skku.edu) 


\section{Methods}

\section{Measurement of dissolved $\mathrm{CO}_{2}$ in acetone by dissolved $\mathrm{CO}_{2}$ titration kits}

Changes in the amount of $\mathrm{CO}_{2}$ dissolved in acetone according to the change in the amount of CDI were measured by dissolved $\mathrm{CO}_{2}$ titration kits (Carbon Dioxide Titrets Kit, CHEMetrics, Inc.). According to the manual, since metal ions can cause a false positive result, no cerium nitrate hexahydrate was added in acetone. To make a similar reaction condition, 108 $\mu \mathrm{l}$ of DW, the equivalent amount of water in $1 \mathrm{mmol} \mathrm{Ce}\left(\mathrm{NO}_{3}\right)_{3} \cdot 6 \mathrm{H}_{2} \mathrm{O}$, was added to $25 \mathrm{ml}$ of acetone (Solution A). Solution B was prepared by dissolving $0,0.5,1$, or $1.5 \mathrm{mmol}$ of CDI in $25 \mathrm{ml}$ of acetone. To determine the effect of extra imidazole on the titration kits, 0 or $2 \mathrm{mmol}$ of imidazole (IM) was added into Solution B. After vigorous mixing of Solution A and Solution $\mathrm{B}$ at room temperature for $5 \mathrm{~min}, 20 \mathrm{ml}$ of the mixture was transferred into the new vial (Solution C). After adding 2 drops of A-1900 Activator Solution into Solution C, a small amount of Solution C was drawn by an assembly of Titret and Titrettor (the component of the kit) until the color of the ampoule changed from pink to colorless permanently. When the color of the ampoule became permanently colorless, the amounts of dissolved $\mathrm{CO}_{2}$ were measured by reading the scale of the ampoule.

\section{Measurement of the amount of $\mathrm{CO}_{2}$ generated during the reaction according to the change in the amount of water}

The experimental setup was prepared with slight modifications via previously reported methods. ${ }^{1}$ CDI solution, prepared by dissolving $6 \mathrm{mmol}$ of CDI in $25 \mathrm{ml}$ of acetone, was added to $25 \mathrm{ml}$ of acetone solution containing 108,308 , or $708 \mu \mathrm{l}$ of DW with vigorous stirring at room temperature for $20 \min (108 \mu \mathrm{LW}$ : the equivalent amount of water in $1 \mathrm{mmol}$ 
$\left.\mathrm{Ce}\left(\mathrm{NO}_{3}\right)_{3} \cdot 6 \mathrm{H}_{2} \mathrm{O}\right)$. In the case of the reaction with cerium nitrate hexahydrate solution, the above-mentioned CDI solution was mixed with $25 \mathrm{ml}$ of acetone solution containing $600 \mu \mathrm{l}$ of DW and $1 \mathrm{mmol}$ of cerium nitrate hexahydrate solution (total amount of DW: $708 \mu \mathrm{l}$ ). The reactor for the above reactions was connected to another glass vial containing $20 \mathrm{ml}$ of $1 \mathrm{M}$ $\mathrm{NaOH}$ aqueous solution by PTFE tube $(\varnothing 0.8 \mathrm{~mm} \times \varnothing 1.6 \mathrm{~mm})$. One end of the PTFE tube was immersed in $\mathrm{NaOH}$ solution so that $\mathrm{CO}_{2}$ bubbles generated during the reaction could be observed, and the generated bubbles were counted from the recorded video. ${ }^{2}$ The amounts of $\mathrm{NaOH}$ consumed in the $\mathrm{NaOH}$ solution after 20 min of the reaction due to the reaction with dissolved $\mathrm{CO}_{2}$ from the $\mathrm{CO}_{2}$ bubbles were measured by titrating with $1 \mathrm{M} \mathrm{HCl}$. The endpoint of the titration was determined by the color change from pink to colorless of phenolphthalein.

\section{Investigation for the effect of calcination temperature and heating rate on the properties of Cal-CeONPs}

For the calcination, $\mathrm{CeCb}$ nanosaucers $(\mathrm{Ce}: \mathrm{CDI}:$ imidazole $=1: 1: 4$ in the reaction) were used. The calcination temperature was controlled from $300{ }^{\circ} \mathrm{C}$ to $500{ }^{\circ} \mathrm{C}$ at a heating rate of $10{ }^{\circ} \mathrm{C} / \mathrm{min}$. In addition, in raising the calcination temperature to $500{ }^{\circ} \mathrm{C}$, the heating rate was changed to 1,5 , and $10^{\circ} \mathrm{C} / \mathrm{min}$, respectively. After the calcination process, X-Ray powder diffraction (XRD) patterns were obtained using a multipurpose X-ray diffractometer (Smartlab, Rigaku Corporation). 


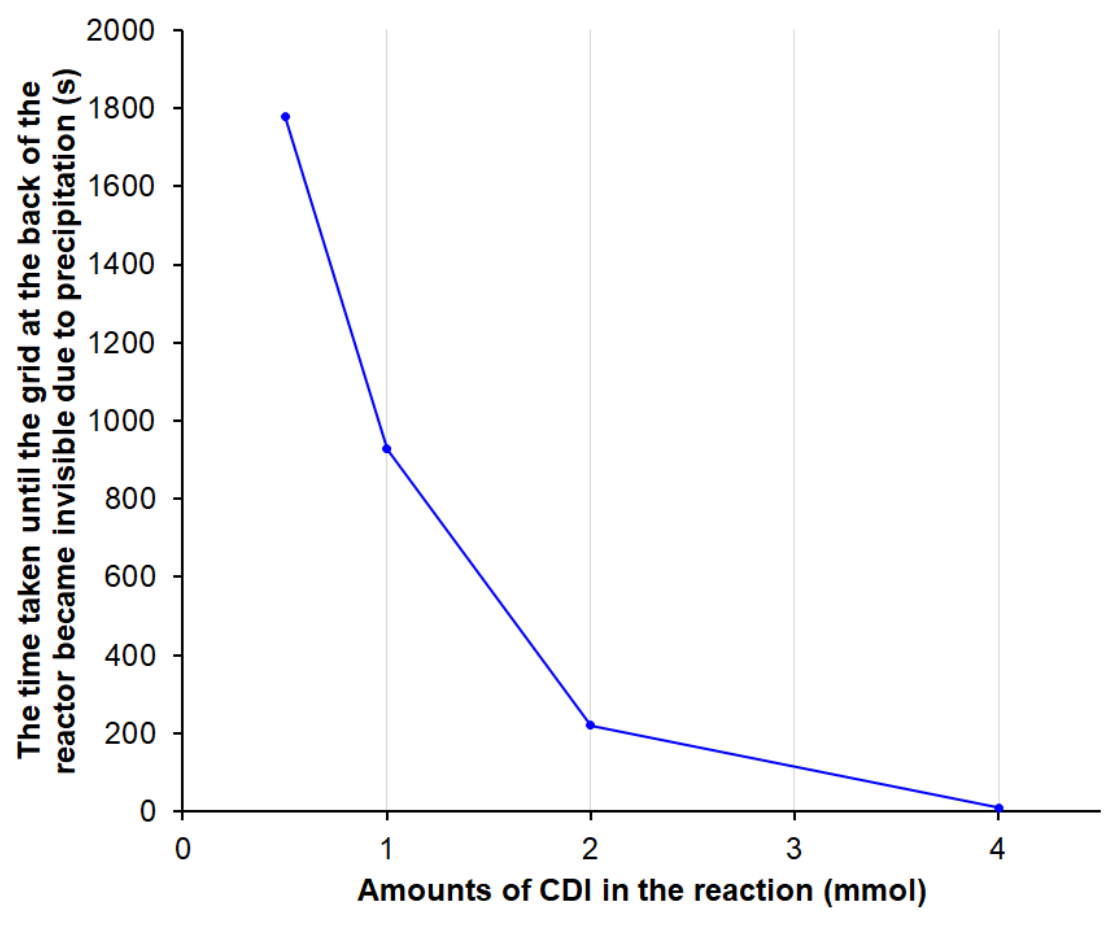

Figure S1. After the addition of CDI, the time taken until the grid at the back of the reactor became invisible to the naked eye due to precipitation was measured. The reaction of synthesizing $\mathrm{CeCb}$ nanoplates using $0.5,1,2$, and $4 \mathrm{mmol}$ of $\mathrm{CDI}$ was used for these measurements.

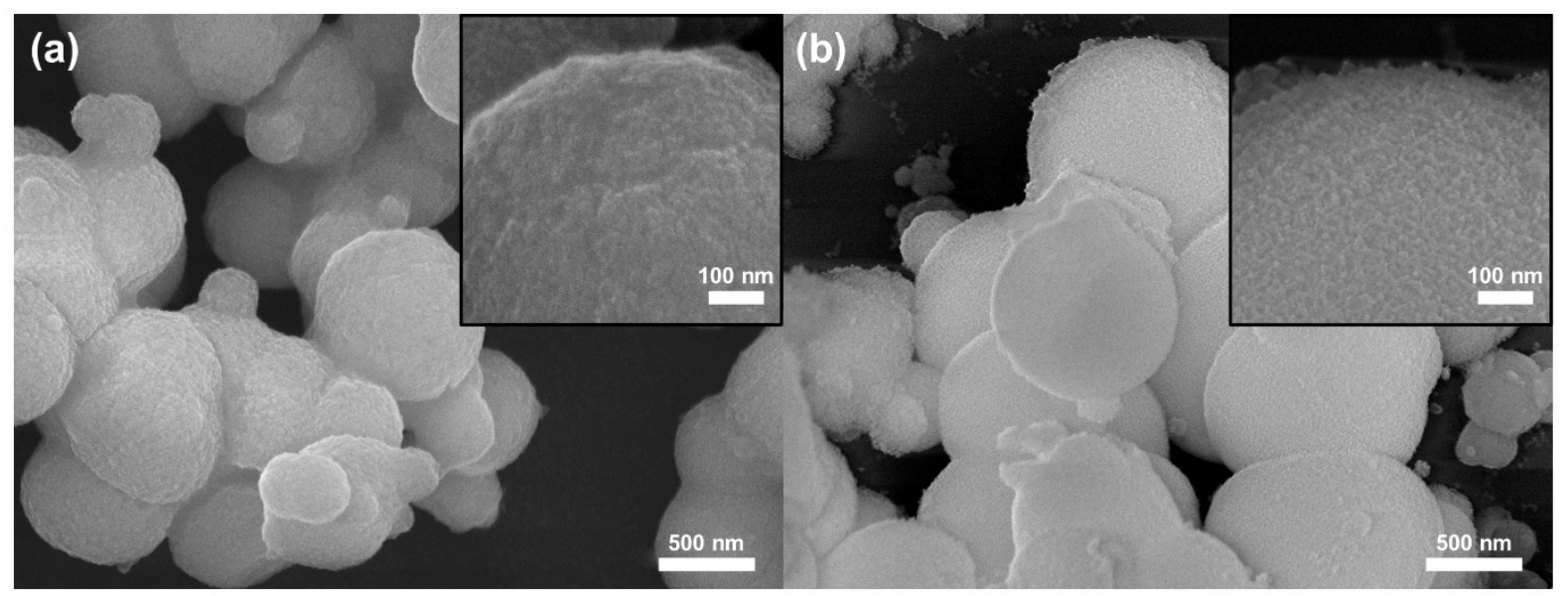

Figure S2. SEM images of nanoparticles synthesized by reaction in which the ratio of Ce and CDI is (a) 1:0.5 and (b) 1:1. 


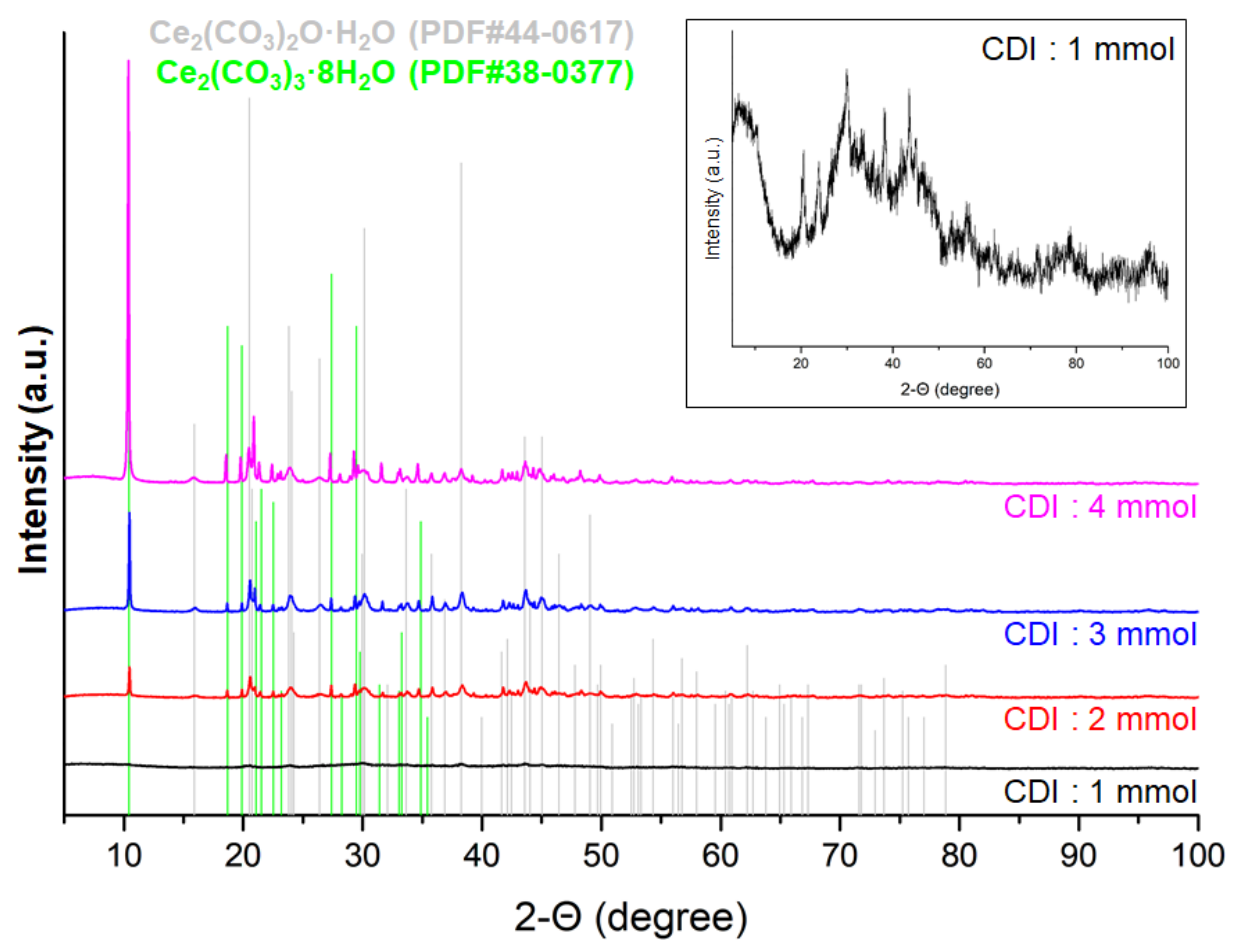

Figure S3. XRD patterns of the $\mathrm{CeCb}$ nanoplates obtained from the reaction using 1, 2, 3, and $4 \mathrm{mmol}$ of CDI. All products were reacted for $3 \mathrm{~h}$ at room temperature in acetone. XRD pattern of the $\mathrm{CeCb}$ nanoplate obtained from the reaction using $4 \mathrm{mmol}$ of $\mathrm{CDI}$ is same to that of Fig. 2(c), but it is shown for peak height comparison. 
(a)

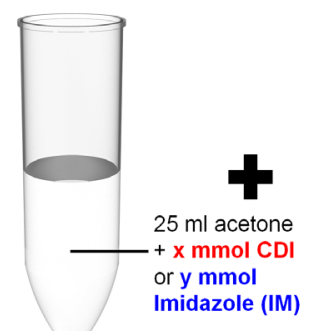

Solution B

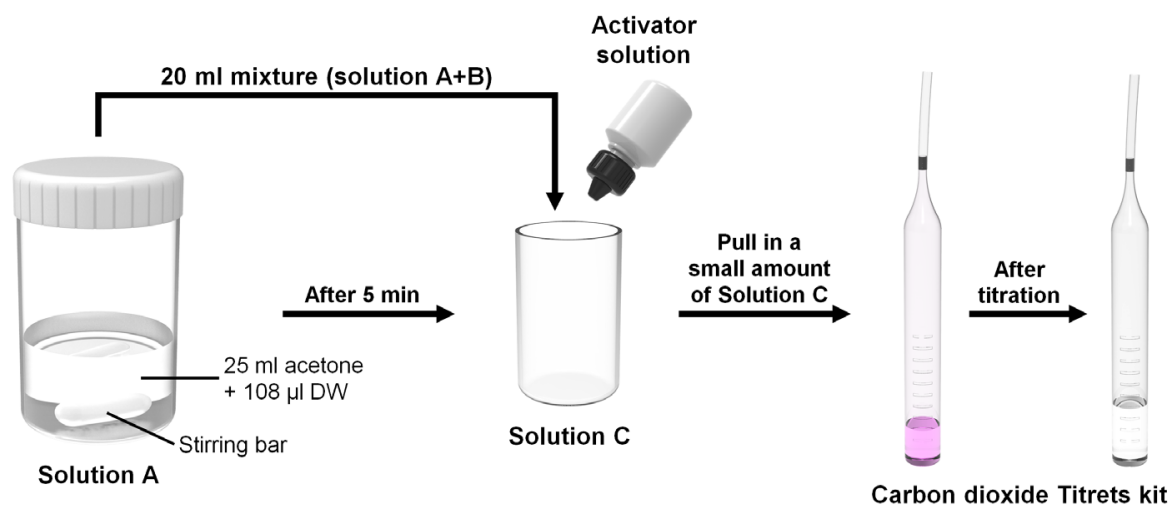

(b)

Amount of DW in Solution $A=108 \mu \mathrm{l}$ (equivalent to the

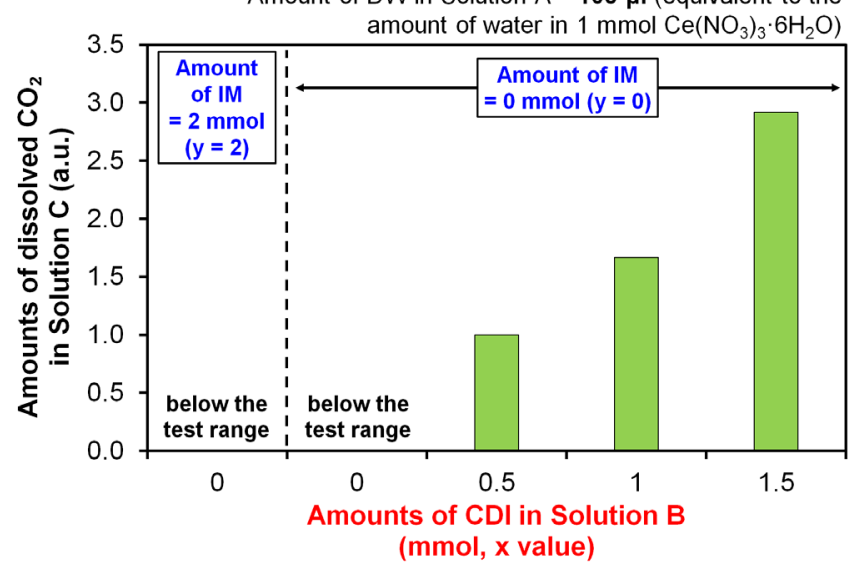

Figure S4. The amounts of dissolved $\mathrm{CO}_{2}$ in acetone. (a) Schematic illustration of the experimental procedure of the dissolved $\mathrm{CO}_{2}$ titration kit and (b) the result of a dissolved $\mathrm{CO}_{2}$ in acetone according to the change in the amount of CDI. 

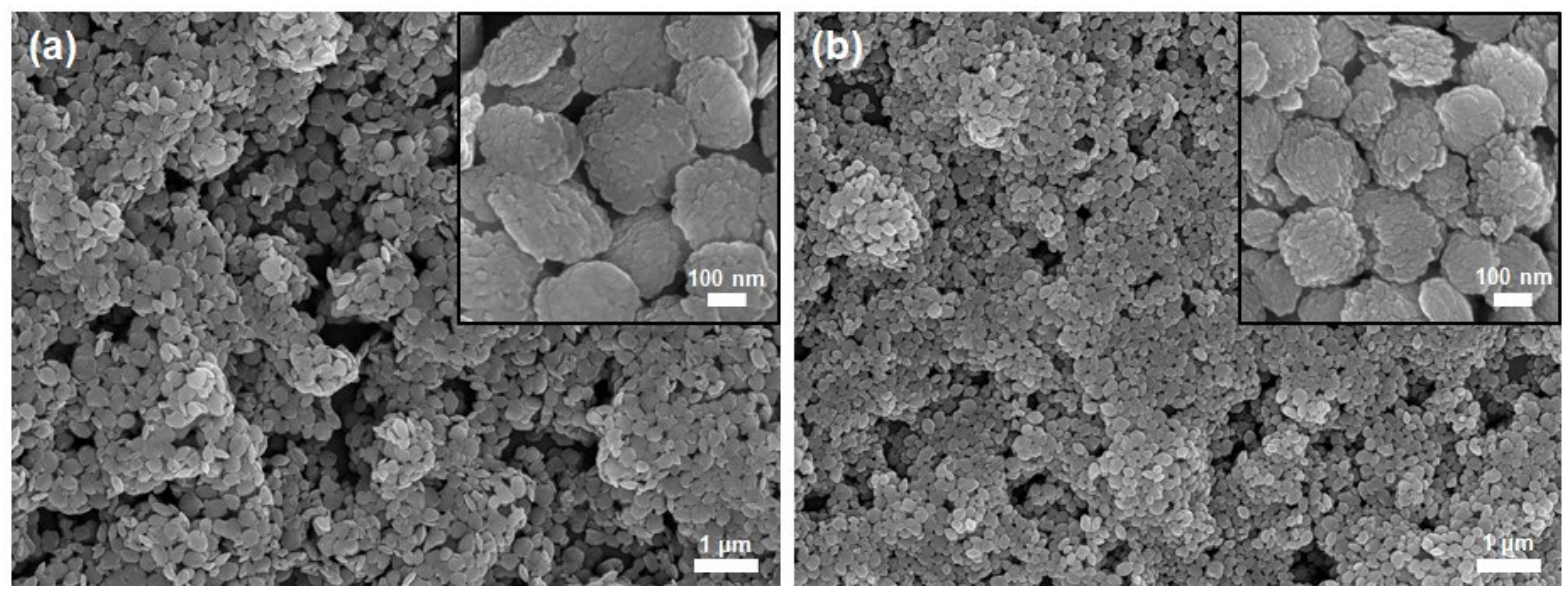

Figure S5. SEM images of the $\mathrm{CeCb}$ nanosaucers obtained from the reaction using (a) 2 and

(b) 4 mmol of imidazole. The moles of cerium nitrate hexahydrate and CDI were fixed as 1 and 1 mmol. Scale bar: $1 \mu \mathrm{m}$ (inset: $100 \mathrm{~nm}$ )

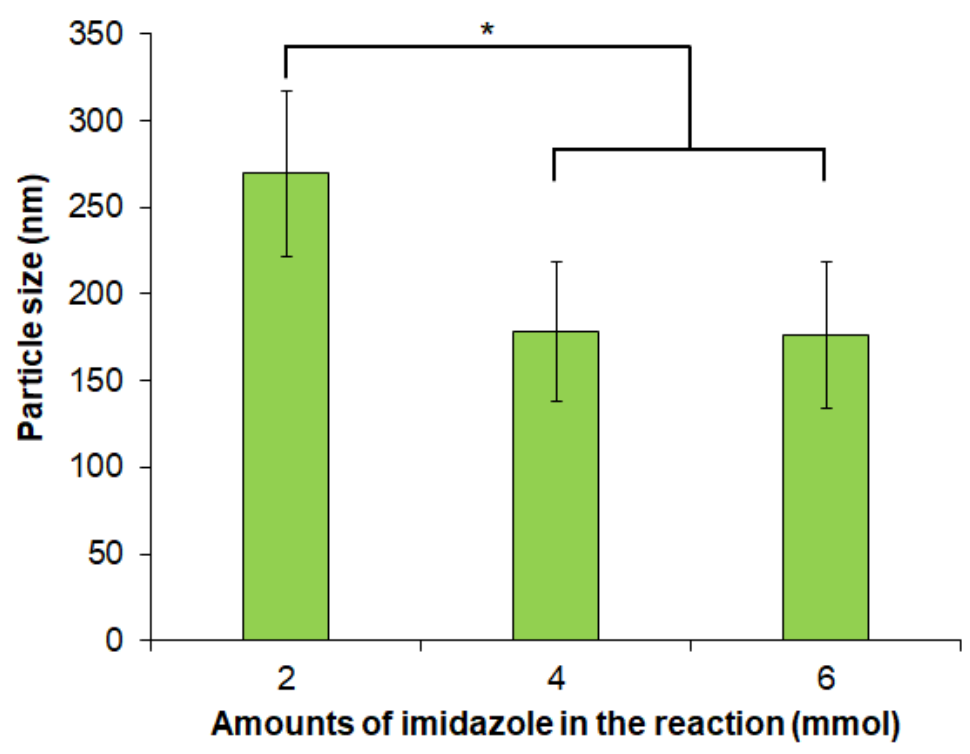

Figure S6. Comparison of particle sizes according to the amount of additional imidazole. The moles of cerium nitrate hexahydrate and CDI were fixed as 1 and $1 \mathrm{mmol}$. All products were reacted for $3 \mathrm{~h}$ at room temperature and the particle sizes were manually measured in SEM images by Image $\mathrm{J}$ software. ${ }^{*} \mathrm{P}<0.05$. 


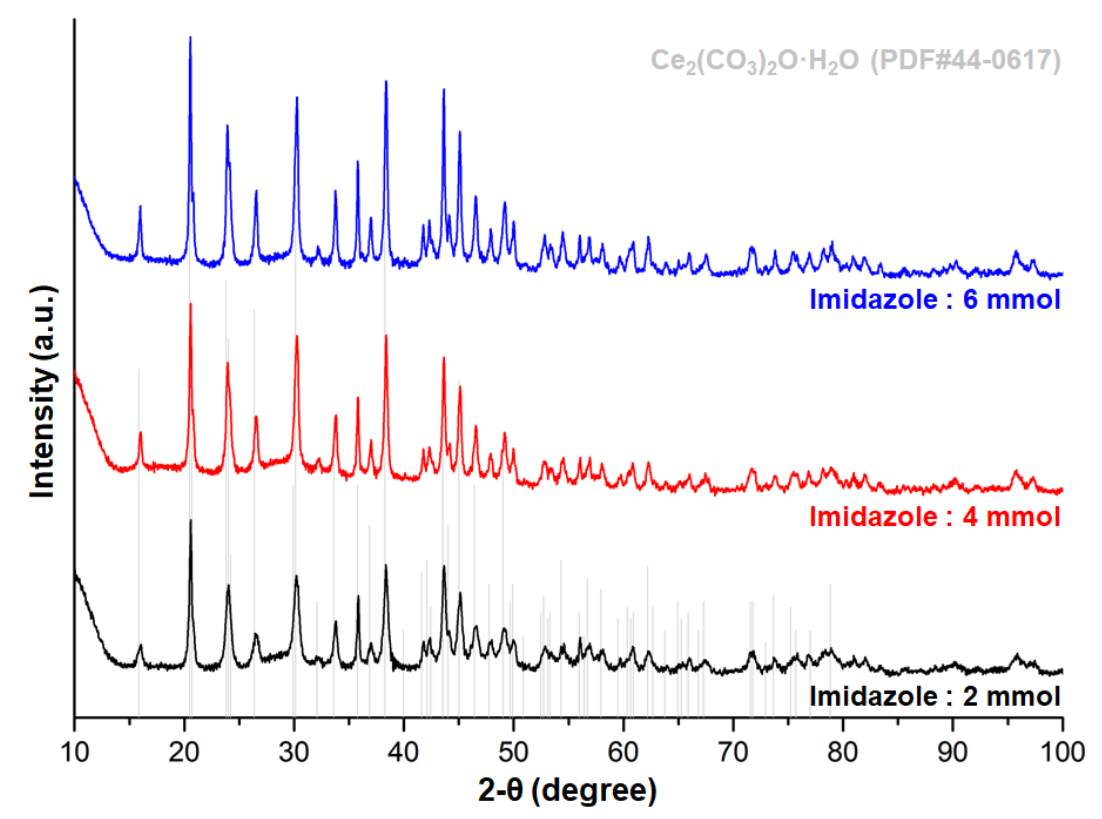

Figure S7. XRD patterns of the $\mathrm{CeCb}$ nanosaucers obtained from the reaction using 2, 4, and 6 mmol of imidazole. The moles of cerium nitrate hexahydrate and CDI were fixed as 1 and 1 mmol. All reactants were mixed for $3 \mathrm{~h}$ at room temperature in acetone. XRD pattern of the $\mathrm{CeCb}$ nanosaucers obtained from the reaction using $6 \mathrm{mmol}$ of imidazole is same to that of Fig. 2(f), but it is shown for peak height comparison.

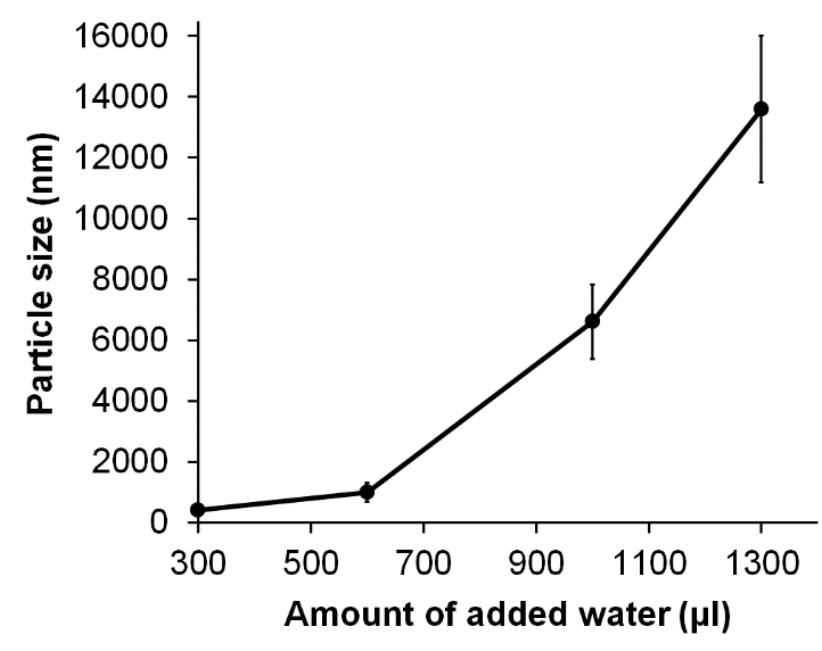

Figure S8. Size changes of the $\mathrm{CeCb}$ nanosaucers (used imidazole : $6 \mathrm{mmol}$ ) according to the amount of added deionized water during the reactions. 

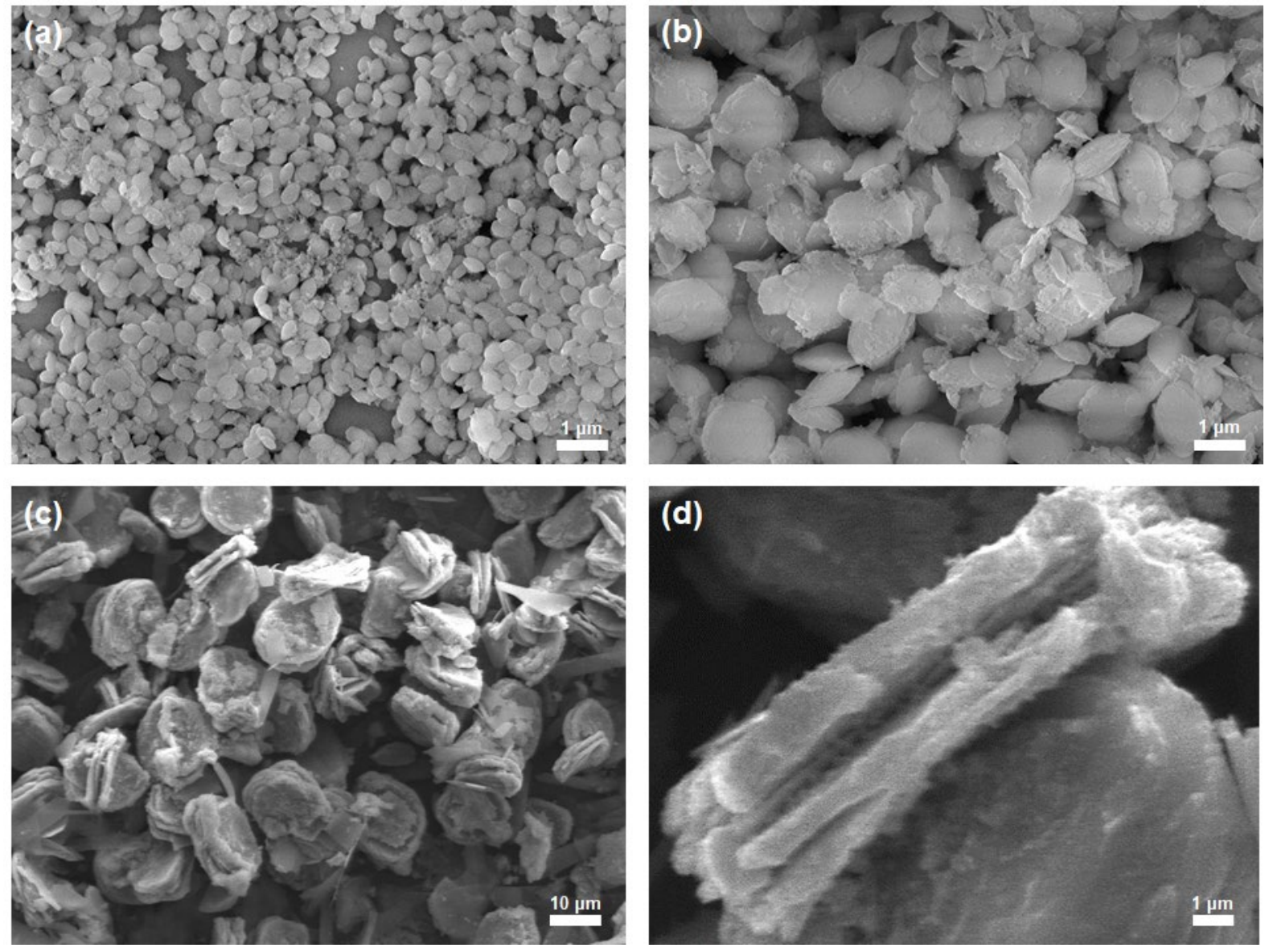

Figure S9. SEM image of $\mathrm{CeCb}$ nanosaucers obtained by adding (a) $300 \mu \mathrm{L}$, (b) $600 \mu \mathrm{L}$, and (c-d) $1300 \mu \mathrm{L}$ of deionized water during the reaction. The moles of cerium nitrate hexahydrate, $\mathrm{CDI}$, and imidazole are fixed as 1, 1, and $6 \mathrm{mmol}$, respectively, and all reactants were mixed for $3 \mathrm{~h}$. Scale bar: $1 \mu \mathrm{m}$ for (a), (b), and (d), and $10 \mu \mathrm{m}$ for (c). 


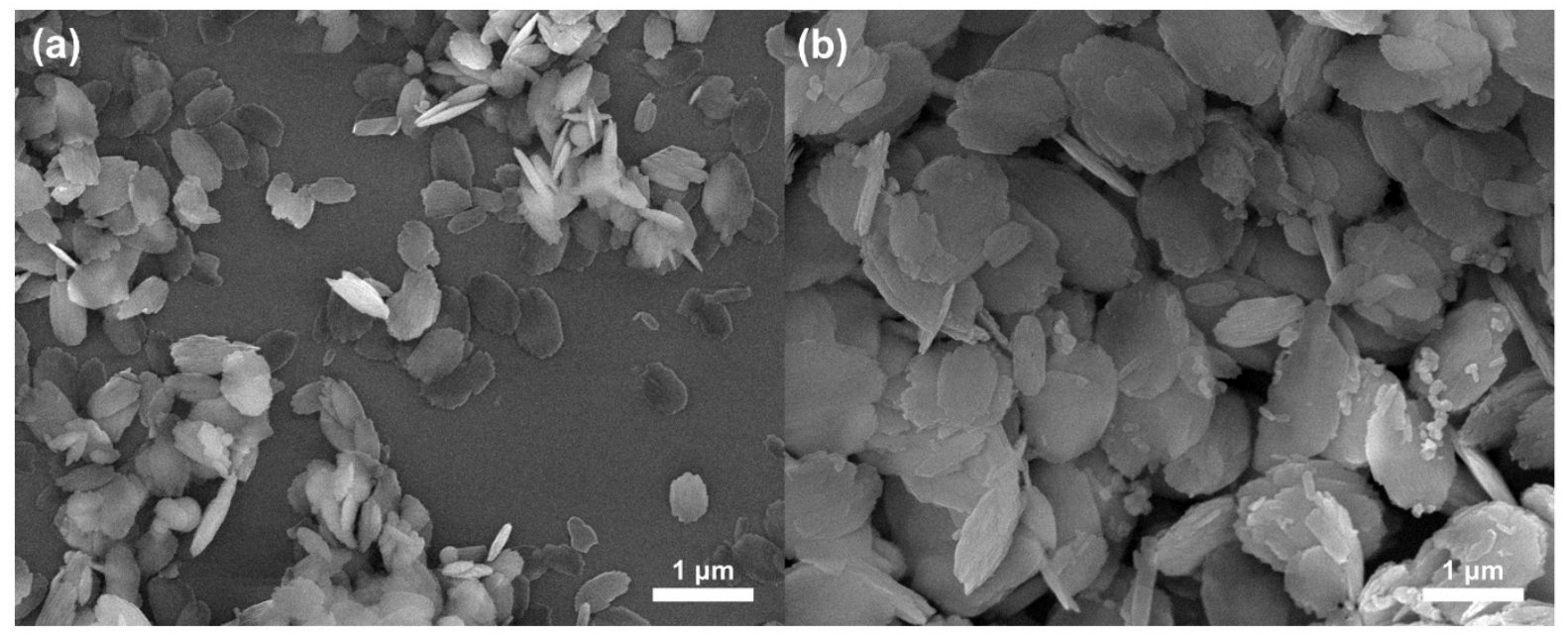

Figure S10. SEM images of the $\mathrm{CeCb}$ nano- and micro-plates made by adding deionized water. The volumes of added deionized water are (a) $300 \mu \mathrm{l}$ and (b) $1000 \mu \mathrm{l}$. The moles of cerium nitrate hexahydrate and CDI are fixed as 1 , and $4 \mathrm{mmol}$, respectively, and all reactants were mixed for $3 \mathrm{~h}$. Scale bar: $1 \mu \mathrm{m}$. 

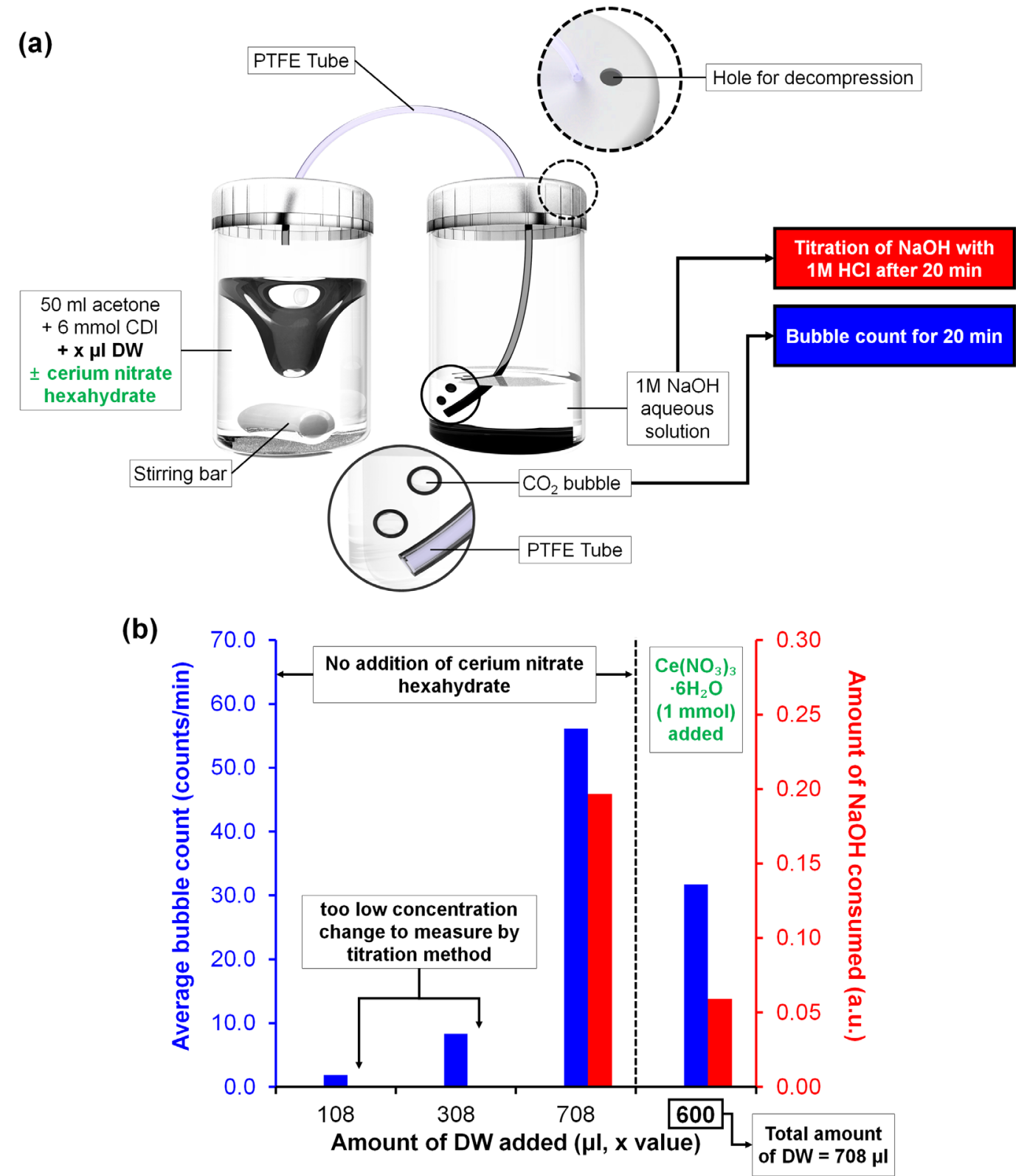

Figure S11. (a) Schematic illustration of the experimental setting to measure the amounts of $\mathrm{CO}_{2}$ generated during the reaction. (b) The results of $\mathrm{CO}_{2}$ generation measured by counting the $\mathrm{CO}_{2}$ bubbles generated during the reaction and titrating the amount of $\mathrm{NaOH}$ consumed after the reaction. 
(a)
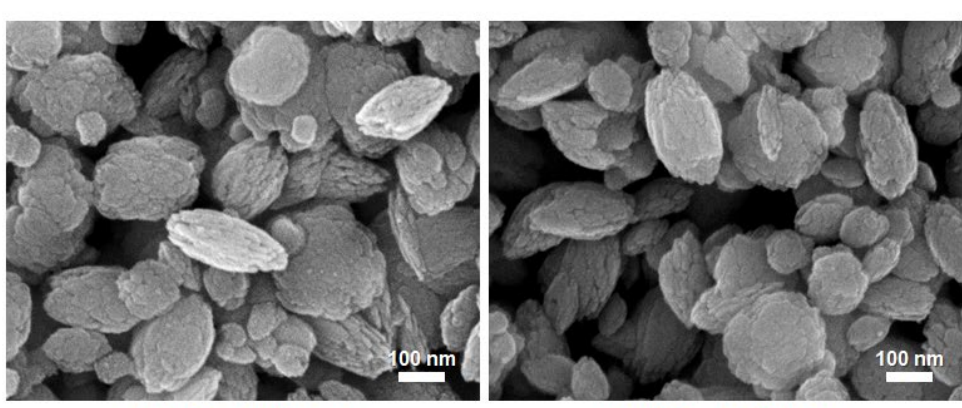

$300{ }^{\circ} \mathrm{C}, 10^{\circ} \mathrm{C} / \mathrm{min}$

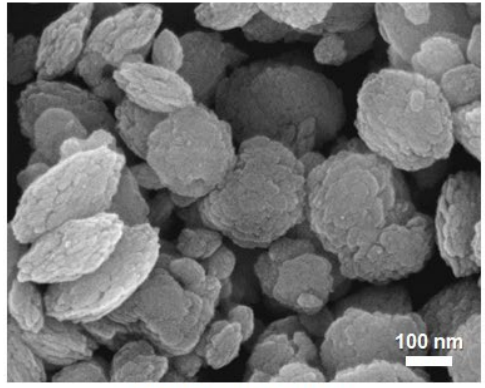

$500{ }^{\circ} \mathrm{C}, 1^{\circ} \mathrm{C} / \mathrm{min}$

(b)

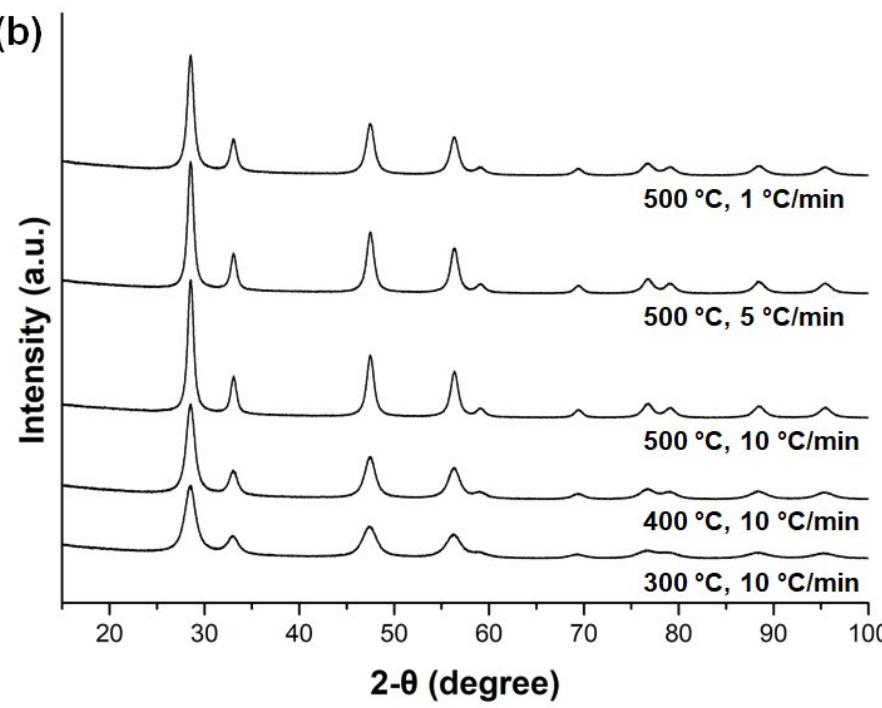

$500{ }^{\circ} \mathrm{C}, 5^{\circ} \mathrm{C} / \mathrm{min}$

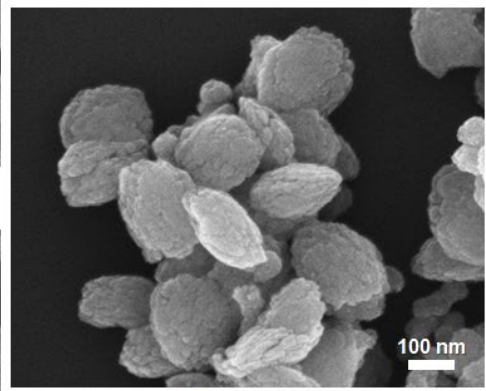

$500^{\circ} \mathrm{C}, 10^{\circ} \mathrm{C} / \mathrm{min}$

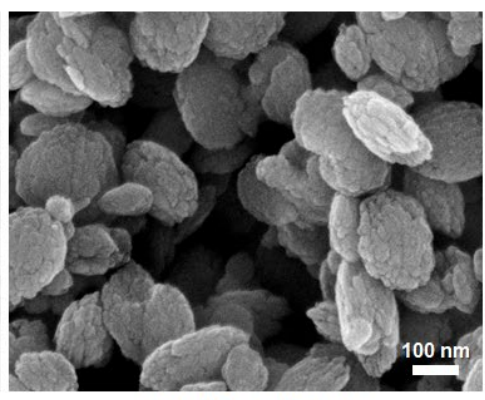

(c)

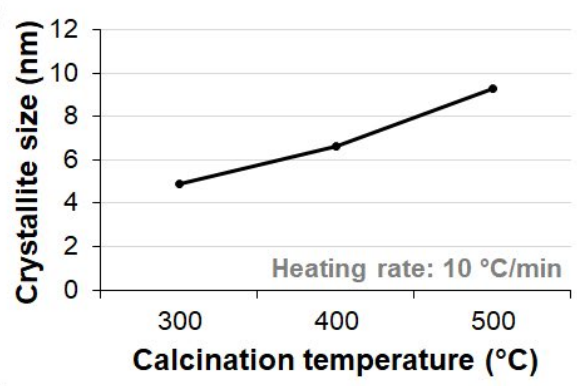

(d)

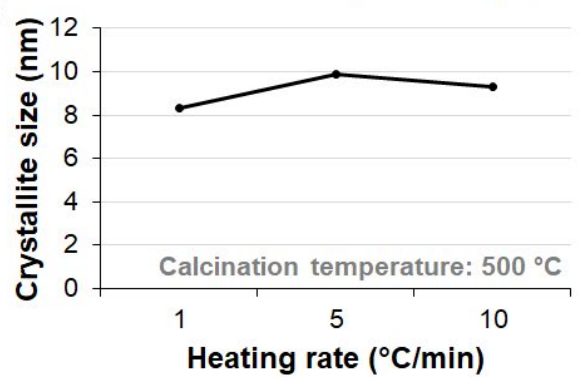

Figure S12. (a) SEM images and (b) XRD patterns of Cal-CeONPs obtained under various calcination conditions. Comparison of crystallite sizes with changes in various (c) calcination temperatures and (d) heating rates. The precursors for the calcination was $\mathrm{CeCb}$ nanosaucers $(\mathrm{Ce}: \mathrm{CDI}:$ imidazole $=1: 1: 4$ in the reaction $)$. 


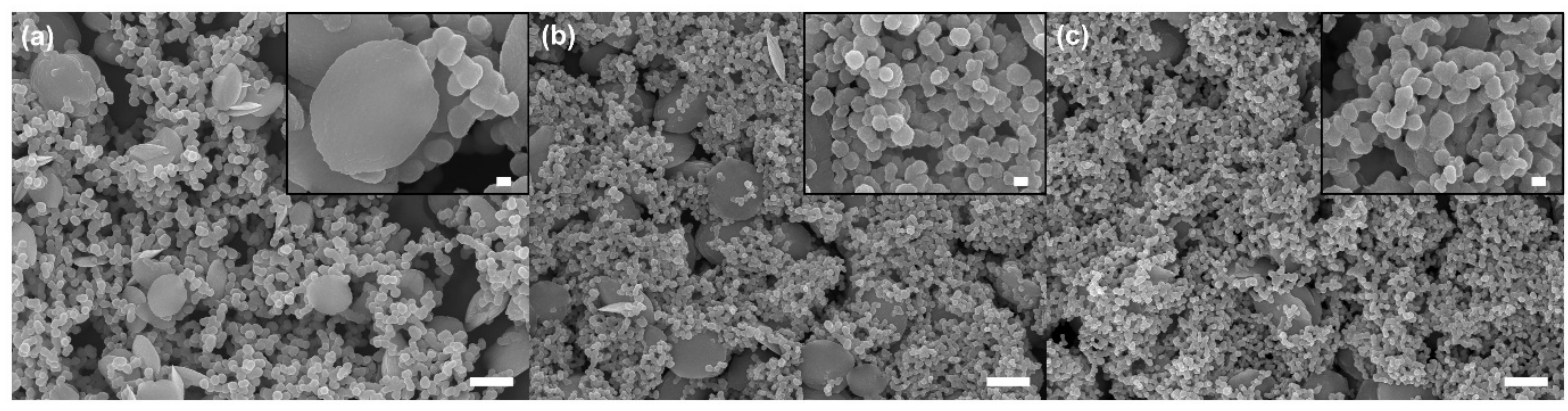

Figure S13. SEM images of the reaction product prepared by adding various amounts of imidazole during the reaction with the moles of cerium nitrate hexahydrate and CDI set to 1 and $0.5 \mathrm{mmol}$, respectively. The moles of additional imidazole are (a) 2, (b) 4, and (c) $6 \mathrm{mmol}$, respectively. All reactants were mixed for $3 \mathrm{~h}$ at room temperature in acetone. Scale bar: $1 \mu \mathrm{m}$ (inset: $100 \mathrm{~nm}$ ).

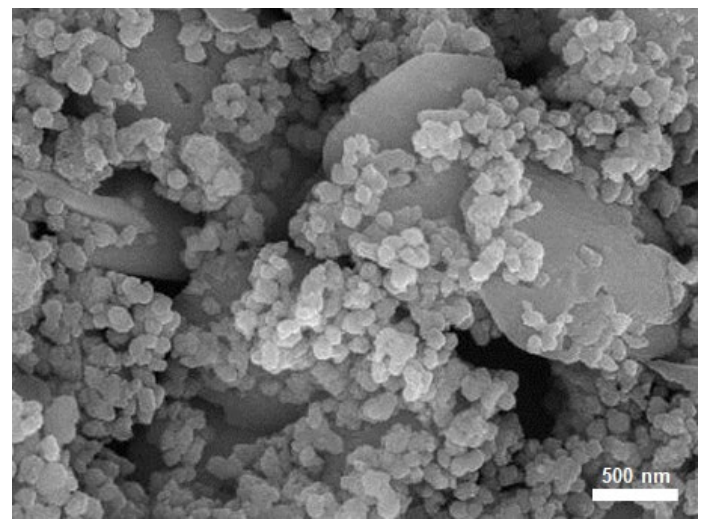

Figure S14. SEM image of the reaction product prepared by the mixing time of $6 \mathrm{~h}$. The moles of cerium nitrate hexahydrate, CDI, and imidazole are set as 1, 0.5, and $4 \mathrm{mmol}$, respectively. It reacted at room temperature in acetone. Scale bar: $500 \mathrm{~nm}$ 


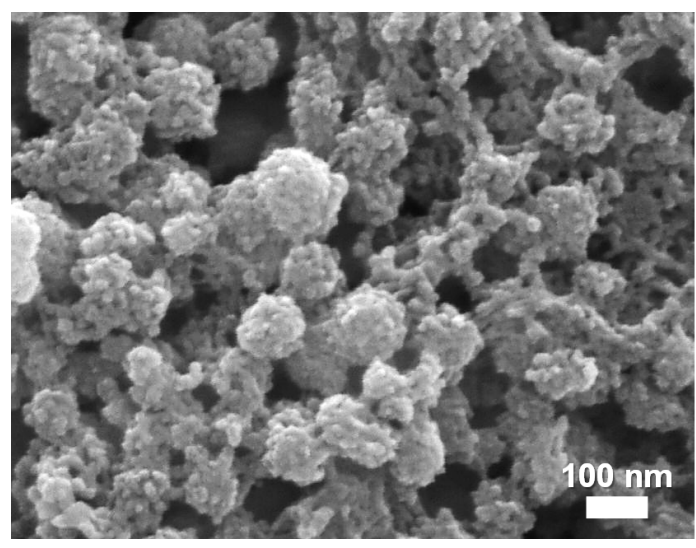

Figure S15. SEM image of the reaction product separated 1 min after the start of the reaction of the synthesis of Ce-CDI-IM CeONPs. The moles of cerium nitrate hexahydrate, CDI, and imidazole are set as 1, 0.5, and $4 \mathrm{mmol}$, respectively. It reacted at room temperature in acetone. Scale bar: $100 \mathrm{~nm}$

(a)

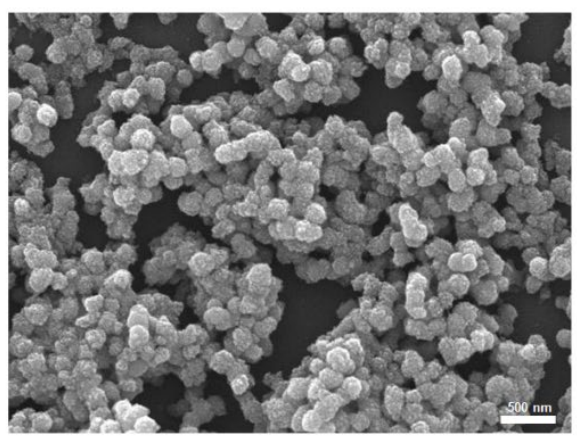

(b)

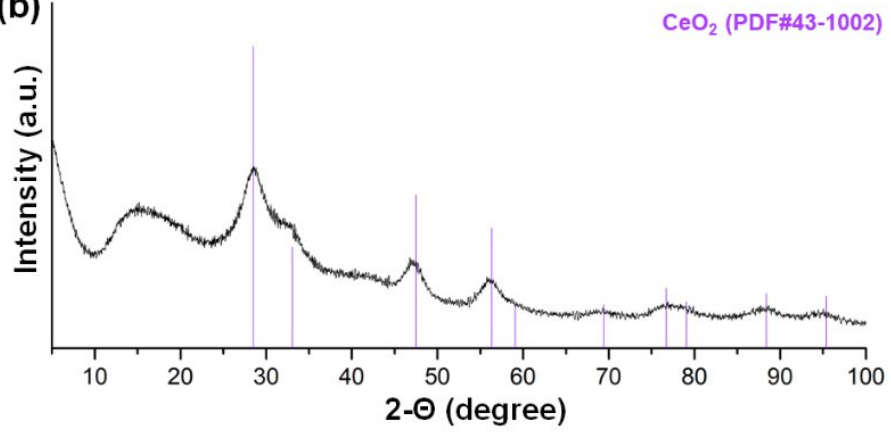

Figure S16. Characteristics of Ce-IM CeNPs. (a) SEM image and (b) XRD pattern of Ce-IM CeNPs. Scale bar: $1 \mu \mathrm{m}$. 


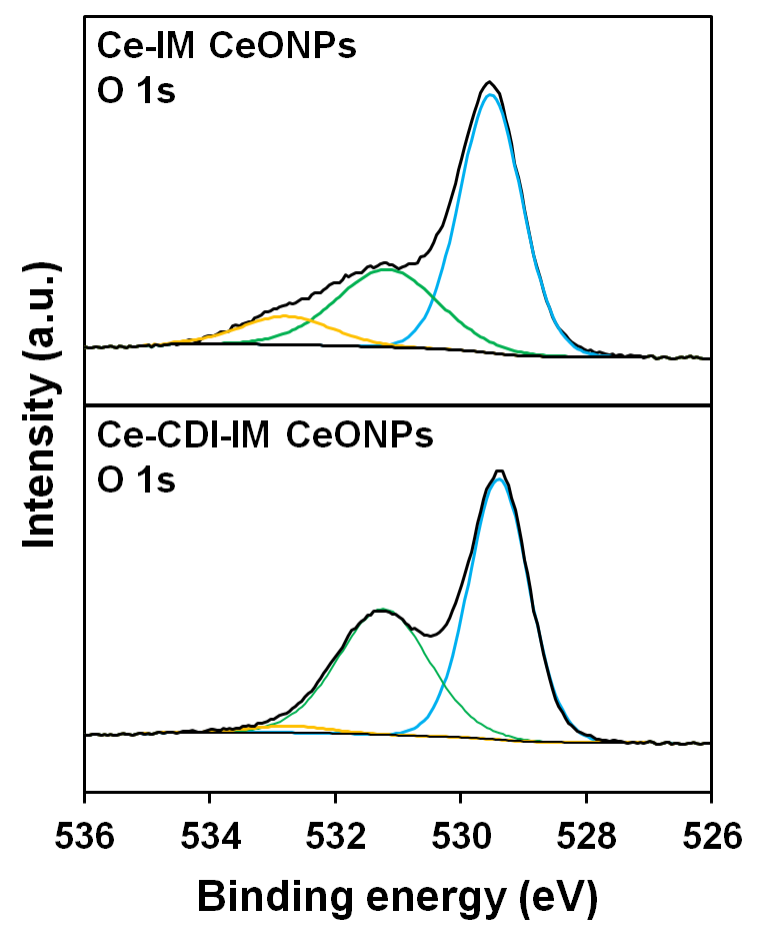

Figure S17. The O 1s XPS spectra of Ce-IM CeONPs (upper panel) and Ce-CDI-IM CeONPs (lower panel).

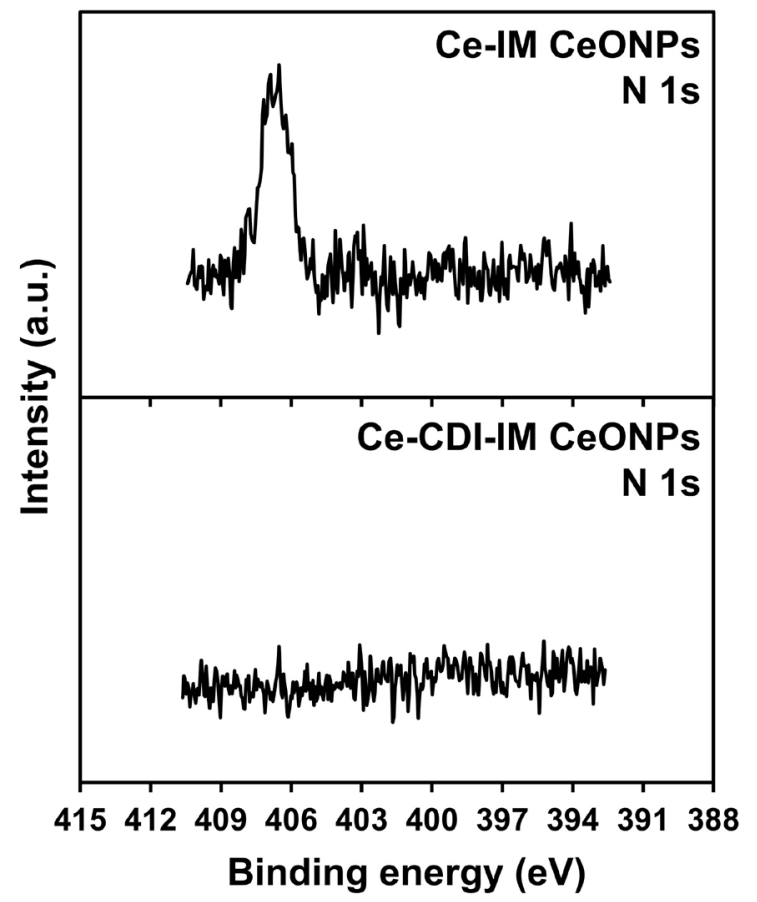

Figure S18. The N 1s XPS spectra of Ce-IM CeONPs (upper panel) and Ce-CDI-IM CeONPs (lower panel). 


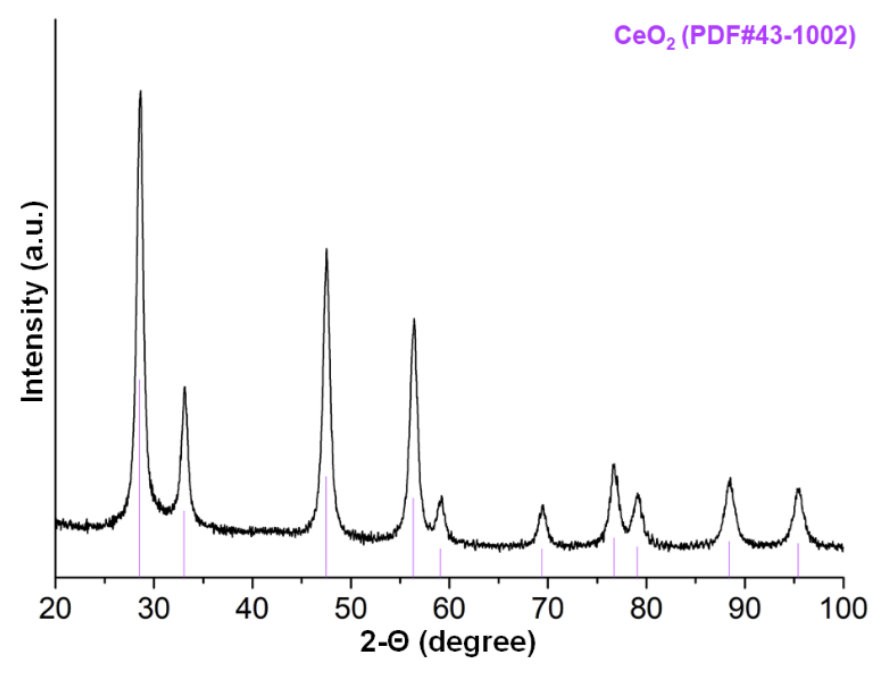

Figure S19. XRD pattern of calcinated Ce-CDI-IM CeONPs.

Video S1. Comparison of time points at which precipitation occurred according to the amount of CDI during the reaction.

Video S2. The effect of the amount of deionized water in the reaction mixture on the time when precipitation occurred during the reaction.

\section{Reference}

1. Crossno, S. K.; Kalbus, L. H.; Kalbus, G. E., Determinations of Carbon Dioxide by Titration: New Experiments for General, Physical, and Quantitative Analysis Courses. Journal of Chemical Education 1996, 73 (2), 175.

2. Ward, M. R.; Jamieson, W. J.; Leckey, C. A.; Alexander, A. J., Laser-induced nucleation of carbon dioxide bubbles. The Journal of Chemical Physics 2015, 142 (14), 144501. 